\title{
Dynamic modeling of the effect of water management on polymer electrolyte fuel cells performance
}

\author{
S. Culubret ${ }^{a, *}$, M.A. Rubio ${ }^{a}$, D.G. Sanchez ${ }^{b}$, A. Urquia ${ }^{a}$ \\ a Departamento de Informática y Automática, Universidad Nacional de Educación a Distancia (UNED), Spain \\ ${ }^{\mathrm{b}}$ Institute of Engineering Thermodynamics, Deutsches Zentrum Fur Luft und Raumfahrt (DLR), 70569, Stuttgart, \\ Germany
}

\section{H I G H L I G H T S}

- Model composed of submodels of channels, GDL, membrane and electrochemical reactions.

- Model validated with spatial distribution of water and current density experiments.

- Accurate model solver is capable to obtain simulations with a low computational cost.

\section{A R T I C L E I N F O}

Article history:

Received 29 December 2018

Received in revised form

10 July 2019

Accepted 19 July 2019

Available online $\mathrm{xxx}$

Keywords:

Dynamic modeling

Simulation procedure

Liquid water

PEFC

Current density

\begin{abstract}
A B S T R A C T
Water management in Polymer Electrolyte Fuel Cell (PEFC) is a key factor in fuel cell performance, and it is an important contributor to the proton exchange membrane durability. Water droplet accumulation in the channel causes non-uniform distribution of gas pressure and spatial inhomogeneity of the local current density in potentiostatic mode. These spatial and temporal fluctuations in the operating conditions imply unequal use of the membrane surface and the catalyst layer, producing uneven degradation and aging of the Membrane Electrode Assembly (MEA). In order to study the dynamic and spatial performance of the fuel cell, a three-level model has been developed. The model is composed of a two-phase, where steam and liquid water drops movement are considered in the channel model; liquid water and gas diffusion are considered in Gas Diffusion Layers (GDLs) model; and finally, the electrochemical reactions are represented in the electrochemical model. The complete model provides a wider understanding of the effect of water on PEFCs and allows to analyze the local current density and the water distribution in response to experimental set-up parameters such as anode and cathode gas flows, total current or channel geometries. The model has been validated using neutron images and segmented cells technique to evaluate the spatial distribution of liquid water and current density in the cell. The developed model and the simulation procedure proposed in this paper allow obtaining long-term dynamic simulations with low computational effort.
\end{abstract}

○ 2019 Hydrogen Energy Publications LLC. Published by Elsevier Ltd. All rights reserved.

\footnotetext{
* Corresponding author.

E-mail addresses: sergi.culubret@gmail.com, sculubret1@alumno.uned.es (S. Culubret).
} 


\section{Introduction}

Water management is a crucial factor in membrane degradation and the durability of other components of the Polymer Electrolyte Fuel Cell (PEFC) [1,2]. Voltage fluctuations caused by the presence of liquid water affect the dynamic behavior $[3,4]$ in a spatially non-homogeneous manner. Water droplet accumulation in the channel causes spatial inhomogeneity of the local current density and generates a non-uniform distribution of gas pressure. Channel clogging by water droplets results in oscillations in the current density.

Optimizing configurations with serpentine, straight parallel, multi serpentine or other channel configurations are widely studied [5,6]. Moreover other investigations to prevent water accumulation are carried out to reduce the effect of water droplets clogging the channel [7].

These spatial and temporal fluctuations in the operating conditions imply unequal use of the membrane surface and the catalyst layer, producing un-even degradation and aging of the Membrane Electrode Assembly (MEA).

The cathode inlet humidity plays an important role in the overall performance as it drives the humidification and drying of the membrane $[8,9]$.

In order to evacuate the liquid water properly in the Gas Diffusion Layers (GDLs), the surface is treated to increase the hydrophobicity. The effect of treatments with Polytetrafluoroethylene (PTFE) or Perfluoropolyether (PFPE) in GDL was analyzed in $[10,11]$.

The spatial distribution of the current density using segmented cells technique was used to evaluate the effect of the spatial distribution of water in the cell $[8,9]$.

In addition, the effect of relative humidity of inlet gases was modeled in these studies. Several models have also been investigated to simulate the different contributors into the cell performance [12-14].

Most of those models are based on implementing a Computational Fluid Dynamics (CFD) solver for the liquid and gas flow problem, which produce models with good accuracy but high cost in computational terms. Extensive investigations about droplet movement modeling were developed $[15,16]$, among others. The model developed in this paper allows to reduce the computational time for an approximation on the droplets movement.

Much more complex models of fuel cells have been already developed. The 3D model developed in [17] obtained stable results after approximately $4 \mathrm{~h}$ of computation with hardware similar to the one used in this paper. The 3D simulation of the stack model developed in [13] converged after around $24 \mathrm{~h}$ with more computing capabilities than the ones employees in this paper.

The model presented in this paper takes into account the effect of the inlet gases humidity and GDL water content in the performance of the cell, using a 1D model developed in [18]. The water produced in the catalyst region is expelled from the GDL on steam and liquid phases. Water removal is considered in previous models, but the effect of the liquid water on the channel was not analyzed. In this paper, water droplet models $[15,16,19]$ have been used to represent the liquid water movement along the channels.
Water flow resistance across the GDL was studied in $[20,21]$ and incorporated on the model developed in this paper; since the water removal in the interface between GDL and the ribs of the collector plates is not allowed, water flow to a channel region of the GDL to be evacuated. Considering the geometrical factors of the GDL, the flow of species on the GDL plane is analyzed in this paper using a 2D diffusion model.

The channel geometry may contribute to the pressure drop and water movement resistance. In this paper, the pressure drop along the channel has been studied considering liquid water in the channel as a disturbance on the channel. The geometry of the channel and the water droplets, considered as obstacles, define the pressures losses produced by the gas flow [22], and without liquid water [4].

In this paper, a simple, but an accurate model to evaluate the performance of a fuel cell, composed a pseudo-3D channel model and a 2D GDL model is presented.

The channel model is a two-phase model, combining the humid gas flow and liquid water droplets moving along the channel. The GDLs, cathode and anode models, consider liquid water and gases flow in the 2D plane, and are connected to the channel model by a gas and liquid interface.

Cathode and anode are linked using a membrane model that considers the effect of the electro-osmotic drag and back diffusion, relating both in terms of the balance of species. The electric current and water generation, and mass balance due to electrochemical reactions are evaluated using the electrochemical model.

The presented simulator presented facilitates studying the effect of the gases and the liquid water on the fuel cell performance. The model takes into account the liquid and gas flow in the GDL, the liquid water/steam balance due to evaporation/condensation phenomena, and the capillarity of the porous media. Modeling of the channel pressure drop, droplet movements and water evaporation to the channel will allow a better understanding of the effects of liquid water and humidification on the fuel cell performance. The focus is put on computational speed to enable fast modeling-testing cycling loops.

\section{Model development}

The model presented in this paper studies the water in the anode and cathode side of the PEFC.

The overall model is divided into four different parts: a) the GDL model, that represents the liquid water and gas transport phenomena; b) the membrane model, that describes the cathode and anode water balance; c) the channel model where liquid water and gases transport are taken into account; and d) the electrochemical model.

Each of these models has entity by its own and can be validated and tested independently. As it will be explained in section Numerical procedure, models are connected sequentially to compose the complete model. Due to this type of strategy, the iteration interval time becomes critical to ensure the proper stability and solution of the problem. 


\section{Model structure}

The model developed in this paper aims to represent the dynamic and spatial behavior of a fuel cell with short simulation time. The time dynamics differences of the species involved in the fuel cell (e.g. the water droplets movement in the channel is significantly slower than the electrochemical reaction of the fuel cell) allow to decouple the complete model in a compilation of smaller models. The complete model of the fuel cell is divided into the following four models. Firstly, the water droplets movement and the gas flow in the fuel cell channels are represented by a 1D(L) model. Considering that the length is significantly longer than the cross-section of the channel, the model is considered one dimensional. The channel model is evaluated in all points of the plane (XY) using the spatial discretization (explained in section Numerical procedure), which resolves a 2D water droplets movement. Secondly, the GDL are represented by a $2 \mathrm{D}(\mathrm{XY})+1 \mathrm{D}(\mathrm{Z})$ model. The gases and water diffusion are studied in the plane (XY) and the expelled and uptake water in steam and liquid phase is analyzed in the perpendicular axis of the plane (Z). Thirdly, the proton conductivity, the water diffusion in the membrane and the balance of the water in anode and cathode are represented as a $1 \mathrm{D}(\mathrm{Z})$ model. And finally, the electrochemical reactions are represented by a OD model. Similarly to the other models, the electrochemical model is evaluated in the discretized layer plane (XY). The simulation time of the above described coupled model is significantly faster than the 3D complete model.

\section{Gas diffusion layer model}

In a PEFC, the cathode and anode channel plates are separated by MEA. The GDL is a porous compound that stiffens the proton exchange membrane and allows the gas to diffuse across it to reach the catalytic layers, and the water to be expelled in steam or liquid form. The GDL model is composed of two diffusion models: the liquid water diffusion and the gases diffusion.

The diffusion coefficient of water and gases differ several orders of magnitude in the GDL [18]. This difference allows to decouple the diffusion models, in order to improve the computational performance of simulation.

The generated water is produced on the cathode catalyst layer and flows through the GDL to the interface with the collector plate. The expelled water is related to capillary pressure of the porous media, defined by Young-Place Eq. (3) $[23,24]$, which defines the drainage produced when the liquid pressure, $P_{\text {liq }}$, minus the pressure of the gas, $P_{g}$, is higher than the capillary pressure, $P_{\text {cap }}$, function of the porous media and the liquid properties, Eq. (1).

The water uptake from the GDL depends on the water content, $s$, the gas pressure, $P_{\text {gas }}$, and the capillary pressure of porous media, $P_{\text {cap }}$. The liquid water is drained if the condition of Eq. (3) is satisfied. The capillary pressure value is negative as the GDL has a hydrophobic treatment $[23,24]$. The water evacuation by capillary pressure produces liquid water on the surface of the GDL in the form of droplets.
$P_{\text {cap }}=\frac{2 \gamma \cos (\theta)}{R_{\text {pore }}}$

$q=\frac{\kappa A}{\mu} \frac{d P}{d x}$

$P_{\text {liq }}-P_{g}>P_{\text {cap }}$

The other liquid water variation phenomena are evaporation Eq. (4) and condensation Eq. (5) from the GDL, depending on the relative humidity on the channel $[8,25]$. The difference between variation water from/to humidity with respect the capillary phenomena is the form in which appears into the channel, steam or water droplet. When the steam phase is generated, it can be condensed in droplet form, if the ambient on the channel becomes saturated.

$\mathrm{S}_{\text {vl,evp }}=k_{\text {evp }} \varepsilon S \frac{\rho_{\text {liq }}}{\mathrm{M}_{\mathrm{H}_{2} \mathrm{O}}}\left(P_{\mathrm{H}_{2} \mathrm{O}}-\mathrm{P}_{\mathrm{H}_{2} \mathrm{O}}^{\text {sat }}\right)$

$S_{v l, c o n}=k_{\text {con }} \varepsilon(1-s) \frac{X_{\mathrm{H}_{2} \mathrm{O}}}{R T}\left(P_{\mathrm{H}_{2} \mathrm{O}}-P_{\mathrm{H}_{2} \mathrm{O}}^{\text {sat }}\right)$

The liquid water removed from the cathode's GDL connects, from a liquid water perspective, the channel and the GDL models. Liquid water uptake for hydrophobic treated GDL is not a symmetric process: the conditions required to penetrate the GDL are more restrictive than the ones needed to be expelled thanks to the surface treatments of the GDL. Liquid water is expelled from the GDL in liquid phase (in droplet shape) and steam phase.

In this work, the liquid reabsorption is considered as a constant rate phenomenon only if the water concentration in the GDL is lower than a certain level. Water droplet reabsorption is an important part of this model, as allows the rehumidification of the cell in the presence of liquid droplets and steam water into the anode or cathode.

$S_{a b s}=\delta_{\text {wmin }} q_{a b s}$

Water diffusion on GDL is driven by the difference on capillary pressure among the GDL. The porosity of the GDL is considered constant and homogeneous. The water flow is modeled by Eq. (7), which describes a liquid flow on a porous media.

In this study, the spatial gradient of pressure, the current density and the water content are analyzed. 2D gas and liquid diffusion on the GDL is taken into account. The water flow on GDL was studied in [20], capillarity diffusion may be expressed by Eq. (7) [26].

$\frac{d P}{d t}=\frac{\kappa}{\varepsilon \mu c_{t}} \frac{d^{2} P}{d x^{2}}$

The capillary pressure, $P_{\text {cap }}$, on the GDL is defined by Leverett's equation, Eq. (9) with respect to the amount of liquid water on the GDL, s, that describes the capillary pressure on porous media for a given saturation (for contact angles over $90^{\circ}$ ) and the material properties described in [18].

$P_{\text {cap }}=\sigma \cos \left(\theta_{s}\right)\left(\frac{\varepsilon}{K}\right) J(s)$ 
$J(s)=1.417 s-2.120 s^{2}+1.263 s^{3}$

The multicomponent $\left(\mathrm{O}_{2}, \mathrm{~N}_{2}\right.$ and $\left.\mathrm{H}_{2} \mathrm{O}\right)$ gas diffusion in GDL is described by Stefan-Maxwell's equation. A multicomponent Fickian model approach of Stefan-Maxwell diffusion [27] is commonly used to reduce the numerical calculations for the multicomponent problem. This approach allows to calculate the pressure differences along the GDL using the Fick's second law of diffusion equation Eq. (10) [28].

$\frac{\partial P}{\partial t}=D_{i, j} \frac{\partial^{2} P}{\partial x^{2}}$

For the sake of simplification and speed solution, a single gas approximation has been done. It is considered that instead of multiple gases diffusing inside the GDL, a single gas with a fixed composition (air) is being transported.

The diffusion coefficient depends on the GDL porosity, $\varepsilon$, and tortuosity, $\tau$, and the water concentration at each point of the GDL, s, which is affecting the porosity, reducing the effective porous section by reducing the pore volume. Hence the gas diffusivity at each point varies depending on the amount of water Eqs. (11) and (12) [29].

$\varepsilon_{0}=\frac{V_{\text {pore }}}{V_{\text {total }}}=\frac{V_{\text {pore }, 0}-\left(V_{\text {total }}-V_{\text {pore }, 0}\right) s}{V_{\text {total }}}$

$D_{\text {eff }}=D \varepsilon^{\tau}$

\section{Membrane model}

The electrolyte membrane separates both the oxygen and the hydrogen allowing only (in its design intentions) protons cross the membrane until reaching the cathode catalyst layer, which produces a reaction between protons and oxygen producing water that has to be expelled by the cathode GDL to the channel. Moreover, some water is diffused across the membrane from the anode side to the cathode side, requiring constant humidification of the anode. The water content on the cathode and anode GDL is linked through the MEA by two phenomena the electro-osmotic drag Eq. (13), which produces a flow that depends on the current generated, and the backdiffusion Eq. (15), which produces a flow that depends on the difference of water concentration. Those phenomena create a dependency with respect to the amount of water on the cathode and the anode.

$J_{e o}=2 n_{d} \frac{j}{2 F}$

$n_{d}=0.0029 \lambda_{m}^{2}+0.05 \lambda_{m}-3.4 \cdot 10^{-19}$

$J_{b d}=-D_{b d} \frac{d \lambda_{m}}{d z}$

\section{Channel model}

The channel is represented by a pseudo-3D model that takes into account the effect of pressure losses due to a) the effect of gas flow and liquid water, b) the effect of geometry of the channels and c) the effect of the water droplets in the flow resistance of gases.
The pressure losses due to the flow of gases and liquid water in a channel is represented by Darcy-Weisbach's equation Eq. (16).

Darcy-Weisbach's equation Eq. (16) describes the pressure losses on a channel for a defined length, $L$, in a tube defined by its hydraulic diameter, $D_{h}$, with a gas flow of density, $\rho$, at a certain gas speed, $u$. In order to consider the humidity, the density of the air is calculated as a mix of the dry air density and water content per free flow volume.

$\frac{\Delta P}{L}=f \frac{\rho u^{2}}{2 D}$

The Darcy friction coefficient, $f$, is calculated in laminar regime using Eq. (17), and in turbulent flow using the Colebrook-White equation, Eq. (18).

$f=\frac{64}{\operatorname{Re}}$

$\frac{1}{f}=-\log \left(\frac{e_{r}}{3.7 D_{h}}+\frac{2.51}{\operatorname{Re} \sqrt{f}}\right)$

The equivalent length method is used to calculate the effect of turns in channels. This method allows to use the DarcyWeisbach's equation to represent other geometries.

The droplets affecting the channel are taken into account by considering them as static obstacles for gas flow model in the channel, reducing the flow section of gas, which increases the pressure losses. This approach was also used in [30] and it simplifies the calculation of the pressure drop due to the presence of water droplets in the channel. By using this strategy simplifies the calculation of the pressure losses, taking into account the droplets presence contribution.

The channel contains the water droplets evacuated from the GDL. Droplet dynamics in PEFC was extensively studied in $[1,15,16,31]$. These models analyze the deformation of the droplet due to a gas flow $\dot{m}_{\text {gas }}$, which is defined by width, $w_{c}$, and height, $H_{c}$, of channel section and the droplet volume, $V_{d}$. The droplet movement is described by two acting forces a) the dragging driving force of the gas, $F_{d r a g}$; and $b$ ) the adhesion force that holds the droplet in place $F_{a d h}$, Eq. (19).

$m \frac{d^{2} x_{c m}}{d t^{2}}=F_{a d h}-F_{d r a g}$

The deformation of the droplet is defined by three angles: a) the receding angle, $\theta_{r}$; b) the advancing angle, $\theta_{a}$; and c) the static contact angle of the droplet, $\theta_{s}$.

The shape of the droplet is fully defined by the receding, advancing, contact angles and its volume as shown in Fig. 1 [31]. The droplet radius, $R_{d}$, chord length, $c_{d}$, the area $A_{d}$, Eq. (23) and the height, $h_{d}$, Eq. (24) of the droplet are calculated.

$\mathrm{V}_{d}=\frac{\pi \mathrm{D}_{d}^{3}}{24} \frac{2-3 \cos \theta_{s}+\cos ^{3} \theta_{s}}{\sin ^{3} \theta_{s}}$

$c_{d}=\frac{R}{\sin \theta_{s}}\left(1+\sin \theta_{A} \sin \theta_{R}-\cos \theta_{A} \cos \theta_{R}\right)$

$A_{1}=\theta_{A}+\theta_{R}-\sin \left(2 \theta_{A}\right)+\sin \left(\theta_{A}-\theta_{R}\right)$ 

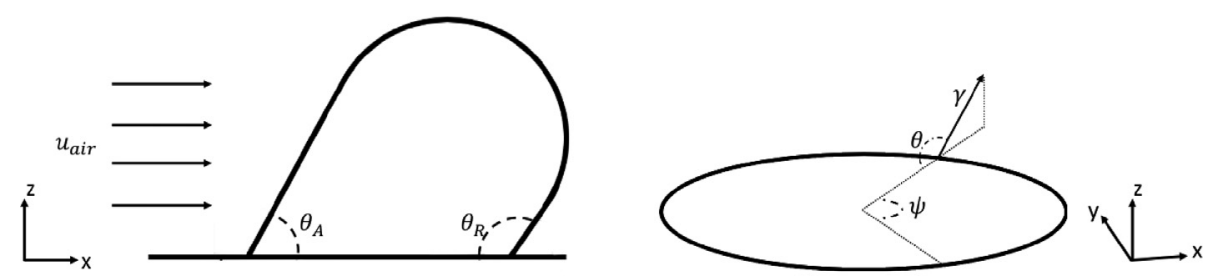

Fig. 1 - Droplet deformation due to air flow inside a channel.

$A_{d}=\frac{R^{2}}{2 \sin \theta_{R}}\left(A_{1} \sin \theta_{R}+\sin ^{3} \frac{\theta_{A}-\theta_{R}}{2} \sin \frac{\theta_{A}+\theta_{R}}{2}\right)$

$h_{d}=R\left(1-\cos \theta_{A}\right)$

Combining Eqs. (23) and (24), a relationship between the advancing and receding angles is calculated in [15], using the grouping parameters, $K_{1}, K_{2}$ and $K_{3}$, Eqs.(25)-(28).

$K_{2}^{2} K_{3}=2 K_{1} \sin \theta_{R}$

$K_{1}=A_{1} \sin \theta_{R}+4 \sin ^{3} \frac{\theta_{A}-\theta_{R}}{2} \sin \frac{\theta_{A}+\theta_{R}}{2}$

$K_{2}=1+\sin \theta_{A} \sin \theta_{R}-\cos \theta_{A} \cos \theta_{R}$

$K_{3}=\frac{1}{\sin ^{2} \theta_{s}}\left(\theta_{s}-\frac{\sin \left(2 \theta_{s}\right)}{2}\right)$

The dragging force is calculated using the Eq. (29), that takes into account the aerodynamic coefficient of the droplet, $C_{d}$, the gas density, $\rho_{\text {gas }}$, and the cross sectional area of the droplet, $A_{d}$; meanwhile the adhesion force, Eq. (30), is calculated with the surface tension of the droplet, $\gamma$, integration over the length of the droplet contact line.

$F_{\text {drag }}=\frac{1}{2} \rho_{\text {gas }} u_{\text {gas }} C_{d} A_{d}$

$F_{a d h}=-\gamma \int_{0}^{l} \cos \theta(l) \cos \psi(l) d l$

The dragging force and adhesion equations are simplified as shown [31], where $H_{c}$ is the channel height and $h_{d}$ the droplet height. In previous equations Eqs. (29) and (30), $\theta$ represents the contact angle and $\psi$ the droplet angle on the plane of the contact surface.

$$
\begin{aligned}
& F_{\text {drag }}= 5.81-4.82 R e_{\mathrm{H}_{c}-h_{d}}+1.67 R e_{\mathrm{H}_{\mathrm{c}}-h_{d}}^{2} \\
&-0.29 R e_{\mathrm{H}_{c}-h_{d}}^{3}+0.03 R e_{\mathrm{H}_{c}}^{4}-h_{d}-8.66 \cdot 10^{-4} R e_{H_{c}-h_{d}}^{5} \\
&-1.43\left(\theta_{\mathrm{A}}-\theta_{\mathrm{R}}\right) R e_{\mathrm{H}_{c}}-h_{d}
\end{aligned}
$$

$F_{a d h}=k \gamma w_{d}\left(\cos \theta_{R}-\cos \theta_{A}\right)$

The constant $k$ depends on the droplet shape. The value of $k$ varies between $\frac{\pi}{2}$ and $\frac{\pi}{4}$ depending if the values are obtained analytically or through finite element [31]. The droplet width is represented by $w_{d}$, where $R_{d}$ and $\gamma$ represent the radius and the tension surface of a spherical liquid droplet respectively. The droplet dynamics is fully described using the Eqs. (19), (31) and (32).

\section{Electrochemical model}

The PEFC electrochemical model relates the current density and the voltage of the cell. The open circuit voltage is described using Nerst's Eq. (33) [32]. The cell over-voltages taken into account are: a) the activation losses, due to the formation of new chemical bonds represented by Tafel equation, Eq. (34); b) the ohmic resistance related with the intrinsic electrical resistance of the membrane Eq. (39) [33]; and c) the concentration losses due to the high demand of reactants and the lack of capacity to supply them Eq. (42) [32]. The partial over-voltages calculated in Eqs. (35), (39) and (40) allow to estimate the cell voltage, Eq. (41).

$E_{0}=-\frac{\Delta G}{n F}$

$E=E_{0}+\frac{R T}{2 F}\left(\ln \left(P_{\mathrm{H}_{2}}\right)+\frac{1}{2} \ln \left(P_{\mathrm{O}_{2}}\right)\right)$

$V_{a c t}=\frac{R T}{2 F} \ln \left(\frac{j}{j_{0}}\right)$

$\sigma_{m}=\left(b_{1}-\lambda_{m} b_{2}\right) e^{b_{3}\left(\frac{1}{3}-\frac{1}{T}\right)}$

Being $\lambda_{m}$, Eq. (37), a function of the water activity, $a_{K}$, in the anode or cathode, Eq. (38) which depends on the total gases pressure, $P$, the molar fraction of steam water, $X_{w, K}$, and the saturation pressure of water at the current conditions, $P^{\text {sat }}$.

$\lambda_{m}=\left\{\begin{array}{l}0.043+17.81 a_{K}-38.85 a_{K}^{2}+36.0 a_{K}^{3}, 0<a_{K}<1 \\ 14+1.4\left(a_{K}-1\right), 1<a_{K}<2\end{array}\right.$

$a_{K}=\frac{X_{w, K} P}{P s a t}$

$\mathrm{V}_{\mathrm{ohm}}=\frac{t h_{m}}{\sigma_{m}} \mathrm{j}$

$\mathrm{V}_{\text {con }}=3 \cdot 10^{-5} e^{-8 j}$

$\mathrm{V}_{\text {fc }}=E-\mathrm{V}_{\text {act }}-\mathrm{V}_{\text {ohm }}-\mathrm{V}_{\text {con }}$

The consumption of reactants and the water generation are calculated from the electrochemical reaction Eq.(42)-(44) [34]:

$\mathrm{S}_{\mathrm{O}_{2}}=-\frac{\mathrm{M}_{\mathrm{O}_{2}}}{4 \mathrm{~F}} \mathrm{j}_{\text {cath }}$ 
$\mathrm{S}_{\mathrm{H}_{2}}=-\frac{\mathrm{M}_{\mathrm{H}_{2}}}{2 \mathrm{~F}} \mathrm{j}_{\text {anod }}$

$\mathrm{S}_{\mathrm{H}_{2} \mathrm{O}}=-\frac{\mathrm{M}_{\mathrm{H}_{2} \mathrm{O}}}{2 \mathrm{~F}} j_{\text {cath }}$

\section{Numerical procedure}

For the spatial and temporal discretization, a Finite Difference Method (FDM) approach has been used to simulate the GDL model. FDM solutions for diffusion phenomena are widely used, thanks to its simplicity on implementation and mesh creation (equally spaced nodes where solution is evaluated). The 2D GDL model is discretized in order to be simulated using a spatial mesh. The mesh is equally spaced on $x$ and $y$ directions, and the mesh element size, is $d x_{m}$ (in current simulations $d x_{m}=$ $0.05 \mathrm{~mm})$. This schema allows to simplify the simulation using a second order spatial approximation and a first order temporal $\mathrm{O}\left(\mathrm{x}^{2}, t\right)$. The Crank-Nicholson is an implicit scheme, solved in two steps and it is a second order spatial and temporal scheme $O\left(x^{2}, t^{2}\right)$ that enables bigger time steps for same diffusivity value.

In order to numerically solve the PEFC model, the GDL is divided in different zones or regions; those regions are a set of GDL elements as shown on (Fig. 2). The use of regions instead of individual elements is performed in order to increase the solution speed of the iterative calculations. If each element of the most restrictive solver were taken into account (in this case the GDL model), the simulation effort would be very high. By assuming that the main interest values vary smoothly enough be can group different elements on a single region and solve for regions count instead of the most restrictive solver discretization. For each region it is considered an average water, $s$, electric conductivity, $\sigma_{m}$, temperature, $\mathrm{T}$, gas pressures, $\mathrm{P}_{\mathrm{O}_{2}}$ and $\mathrm{P}_{\mathrm{H}_{2}}$, and coverage content, $\operatorname{cov}_{\mathrm{i}}$.

The model is able to simulate two operating modes a) galvanostatic mode (constant current) or b) potentiostatic

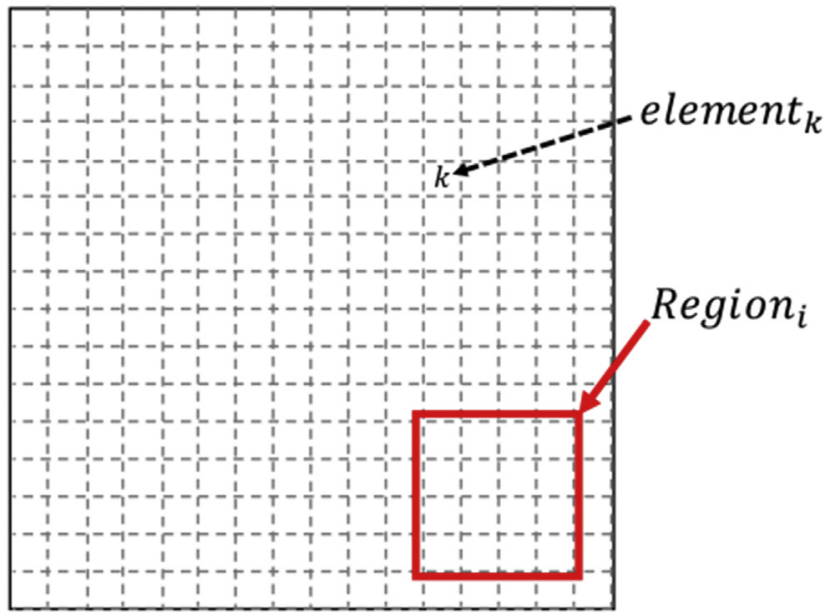

Fig. 2 - GDL are divided in regions and elements. mode (constant voltage). In potentiostatic mode, the region strategy may not be necessary as the current is directly a consequence of the state of each element. In galvanostatic mode, as the cell has to constantly generate the same amount of current, the solution is calculated by iterating until the voltage required to generate such a current is obtained, in this case a reduction on the amount of elements to solve becomes critical.

The simulation procedure is a four-step solver: 1) Channel solver calculates the pressure distribution in the channel, the movement and cluttering of the water droplets; 2)

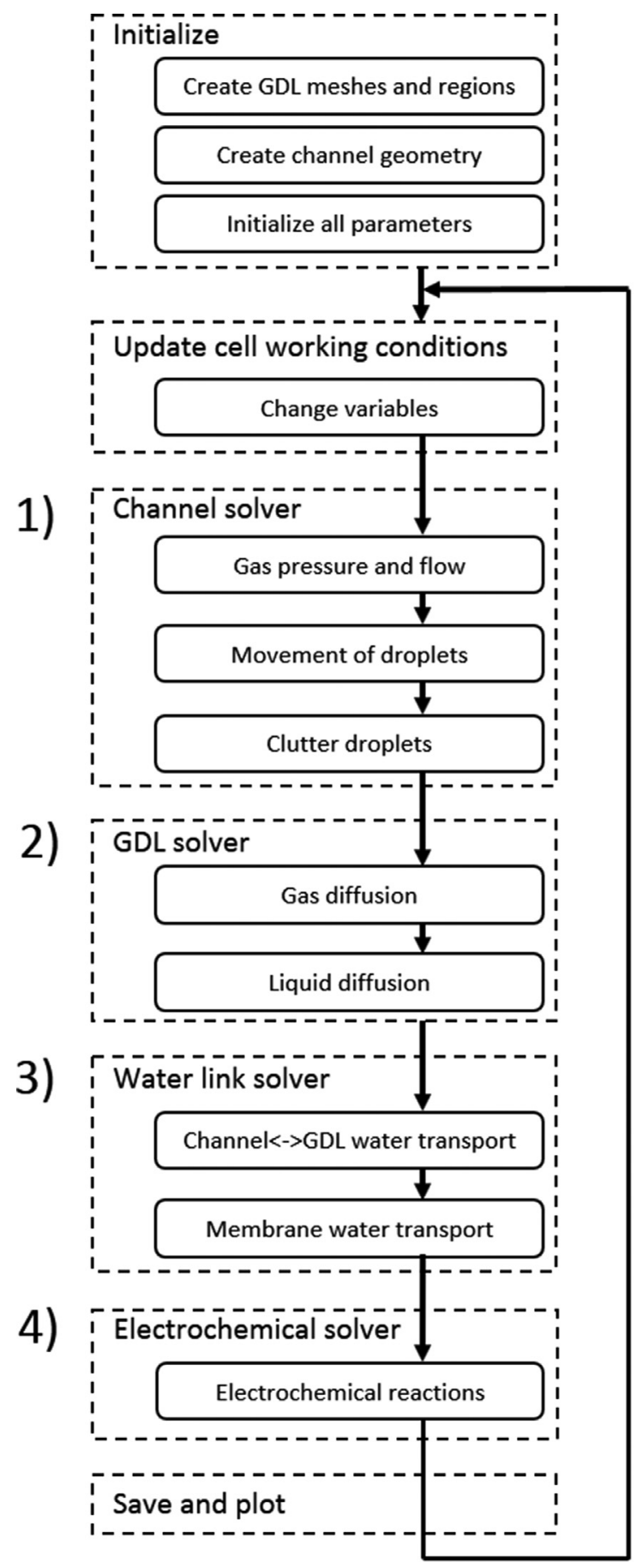

Fig. 3 - Scheme of simulation procedure. 


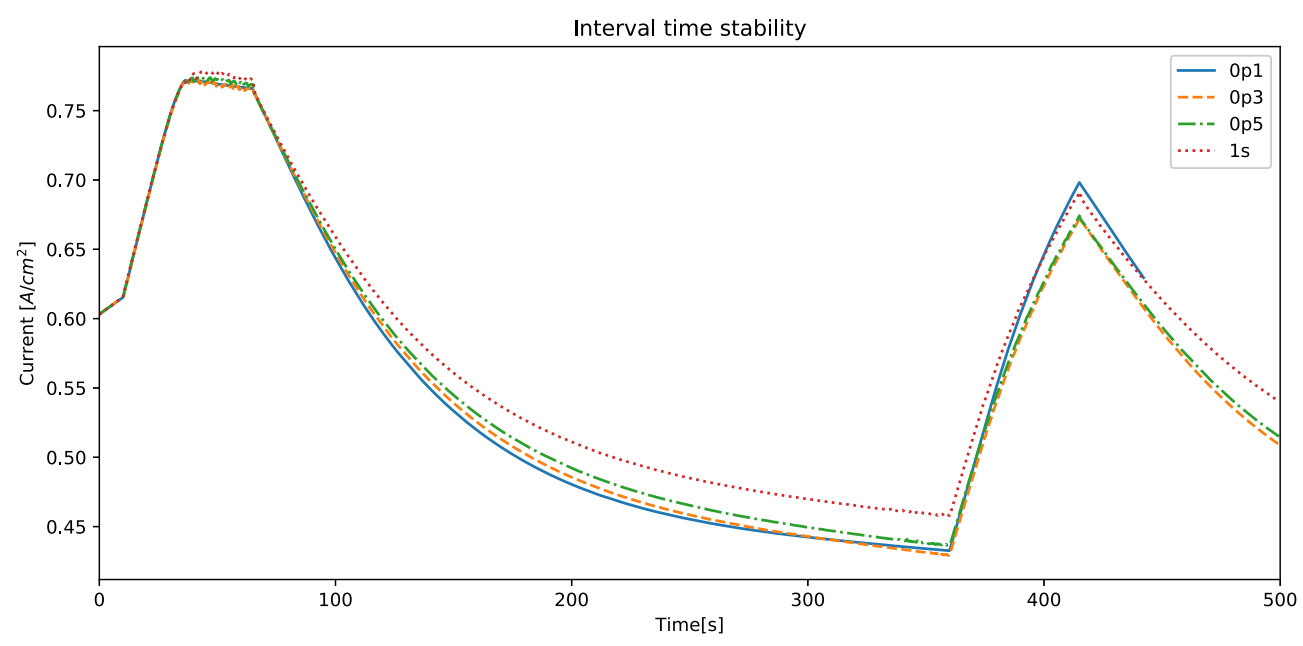

Fig. 4 - Sensibility test of simulation time interval.

GDL solver calculates the gas and liquid water diffusion; 3) Water link solver calculates the transport of water in the membrane between anode and cathode, and the transport of water between the channel and the GDL; and 4) Electrochemical solver calculates the electrochemical reactions of PEFC. Each solver calculates the correspondent model and feeds with the new data the next step of the simulator. The scheme of simulation procedure is shown in Fig. 3. Selecting a time step small enough between cycles the solution becomes independent from this temporal discretization.

For presentation purposes, the channel geometry is drawn as a 2D serpentine. The channel model is discretized along its middle length with a fixed step size $d x_{c}$. The discretization is used to improve the computational effort of the simulation. The channel solver includes the droplets movement. The droplet movement and droplets cluttering require a small time step solver; this approach solves the droplets overlapping and allows to simulate the merge of the droplets.
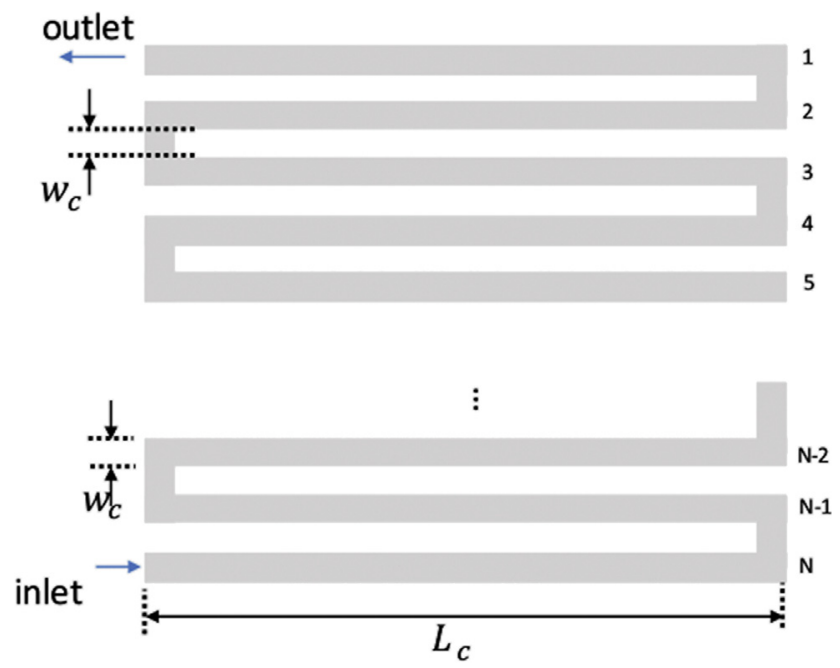

Fig. 5 - Cathode channel geometry used in the simulations.

\section{Model validation and experimental data}

\section{Interval time sensibility}

The implementation is a serialized coupled model. This kind of model is sensitive to the time-interval used as a fraction of the problem to be solved to feed its solution to the model next step. To find a stable time step to solve accurately, a sensitivity tests has been done. The tests consisted on setting a certain target voltage and evaluate the current density for different time-intervals $(0.1 \mathrm{~s}, 0.3 \mathrm{~s}, 0.5 \mathrm{~s}$ and $1 \mathrm{~s})$.

A shorter time-interval of the solver allows to improve the accuracy of the simulation. However, a too short time interval generates simulations that are too slow to achieve the proposed objective. In this work, the use of time-interval values higher than $1 \mathrm{~s}$ produced inconsistent simulation results.

To measure the stability of the solver, the output current density is used as metric for comparison between simulations. The simulations done to check for stability are replicating the experimentation done in [8]. Those experiments are shown in Fig. 4. It can be observed that results under $0.5 \mathrm{~s}$ interval time are sufficiently repeatable, therefore a simulation time step of $0.5 \mathrm{~s}$ is chosen.

The simulation procedure is implemented in Python without multiprocessing nor multi-thread, the simulation-

\section{Table 1 - Parameters used on the simulation.}

\begin{tabular}{lll} 
Parameter & units & Value \\
\hline$d_{t}$ & {$[\mathrm{~s}]$} & 0.5 \\
$d_{x}$ & {$[\mathrm{~mm}]$} & 1 \\
$w_{c}$ & {$[\mathrm{~mm}]$} & 1 \\
$H_{c}$ & {$[\mathrm{~mm}]$} & 1 \\
$L_{c}$ & {$[\mathrm{~mm}]$} & 47 \\
$N_{\text {channels }}$ & {$[-]$} & 25 \\
$H R_{c, a}$ & {$[\%]$} & 50,100 \\
$\theta_{s}$ & {$[\mathrm{rad}]$} & 130 \\
\hline
\end{tabular}




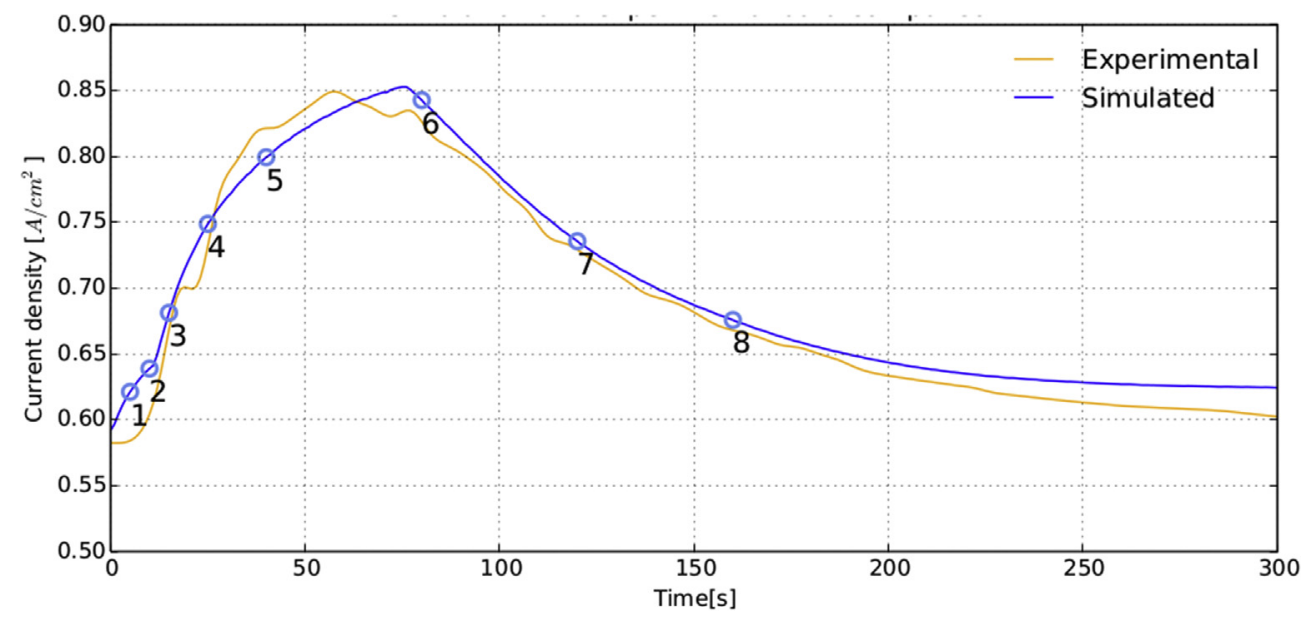

Fig. 6 - Transient behavior of current density from high humidification level to low humidification level for experimental and simulation data.

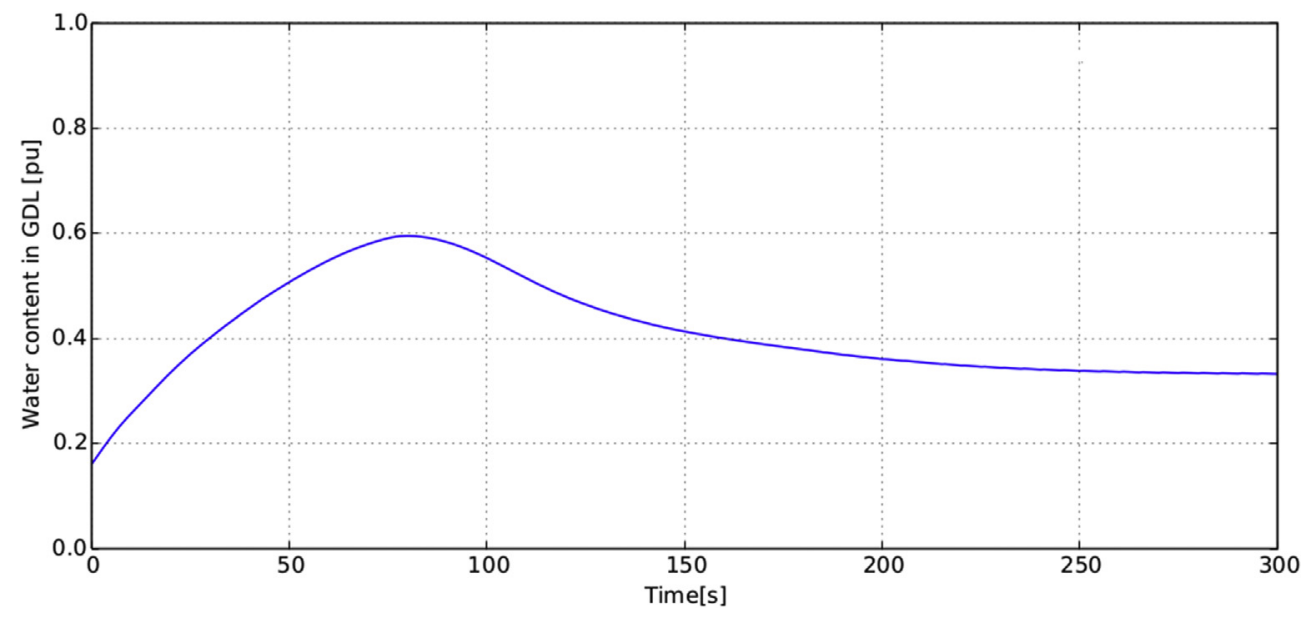

Fig. 7 - Transient average water content on the cell.

simulated time rate is $26: 1$, with a standard deviation of $1.27 \mathrm{~s}$, depending on the amount of droplets in the channel, using a $2.13 \mathrm{GHz}, 4$ cores (which Python only uses 1 processor) and $24 \mathrm{~Gb}$ of RAM memory using Windows 10 operating system. Plots take $18.8 \mathrm{~s}$ to be generated with a standard deviation of $0.9 \mathrm{~s}$, for this reason, the graphics generation has been removed from the main program.

\section{Experimental validation}

The validation of the model has been done with experimental data obtained from a $25 \mathrm{~cm}^{2}$ PEFC using neutron imaging and segmented cell to evaluate the spatial distribution of liquid water and electric current density in humidification-drying cycles [8]. The presented experiment consisted of humidification and dehydration of the cell, using constant gas humidity but injecting water droplets at certain periods (during $40 \mathrm{mg}$ of liquid water during $5 \mathrm{~s}$ ). The studied fuel cell (Fig. 5) has a single serpentine channel of width $w_{c}=1 \mathrm{~mm}$, height $H_{c}=1 \mathrm{~mm}$, length $L_{c}=47 \mathrm{~mm}$, and gravity set on $\mathrm{z}$ axis (assuming that drops are on the GDL surface). Fig. 5 shows a drawing of the modeled channel of the cathode: 25 parallel linear channels with the inlet set at the bottom-left and the outlet at the topleft. The anode channel geometry has the same shape, but the inlet is at the top left and the outlet at the bottom left.

The data obtained by neutron imaging and segmented cell shows an increase on performance when set to high humidification (water droplet injection, $40 \mathrm{mg}$ during $5 \mathrm{~s}$ ) state HS on the cathode, and a drop when setting back to low humidification (stopping the water droplet injection) state LS. The data collected with the segmented cell shows a rapid change from LP to HP when humidity is changed sharply from low to high humidity percentage. However, when humidity is changed back from HP to LP, the transient behavior is slower. This is caused by the velocity of water removal from the GDL driven at high currents. The test done in [8] has been replicated using the model presented in this paper, Fig. 3, and the parameters shown in the Table 1 . The objective of this test is to evaluate the capability of the model to represent the transient performance of a fuel cell, comparing it to experimental data. 
$5 s$

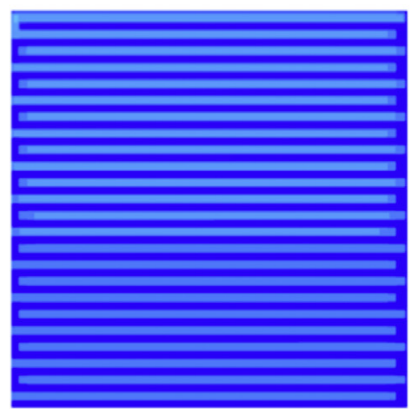

$10 \mathrm{~s}$

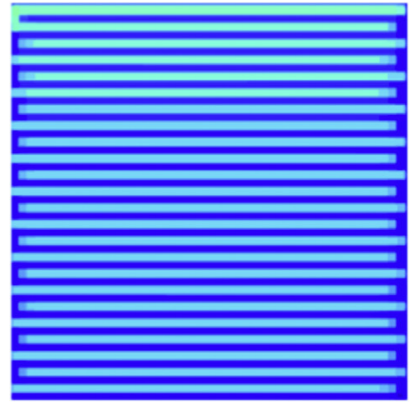

$15 s$

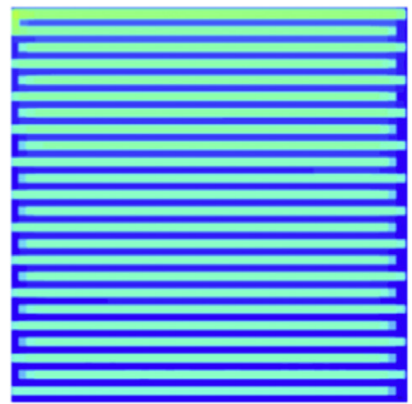

$25 \mathrm{~s}$

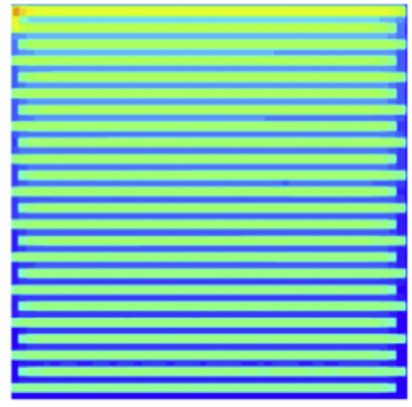

$40 s$

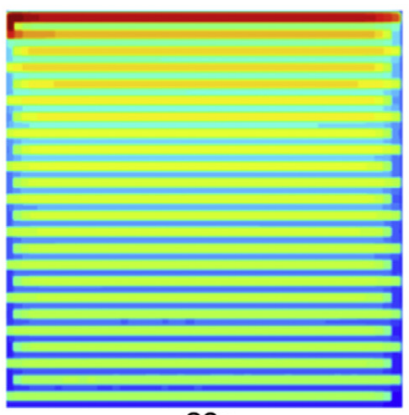

$80 \mathrm{~s}$

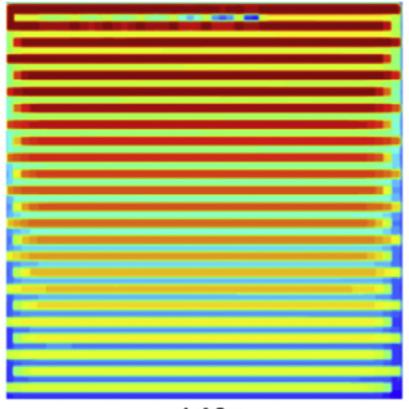

$140 s$

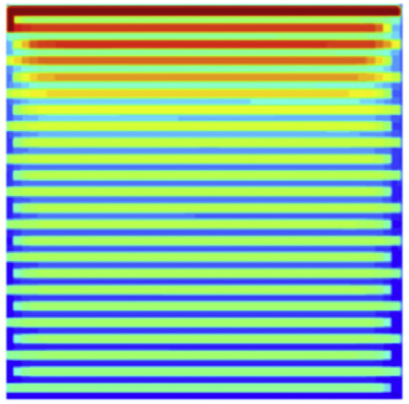

$160 \mathrm{~s}$

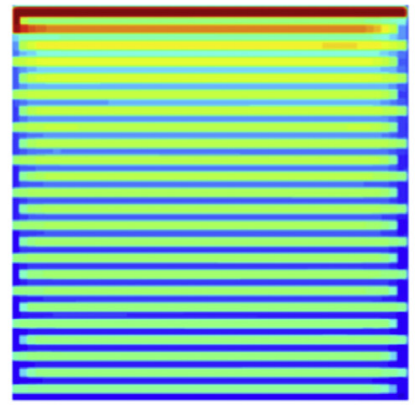

$225 s$
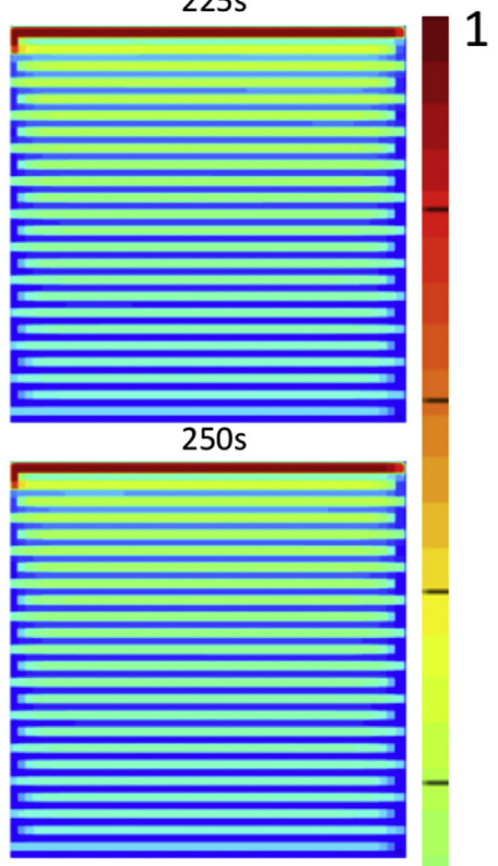

$275 s$

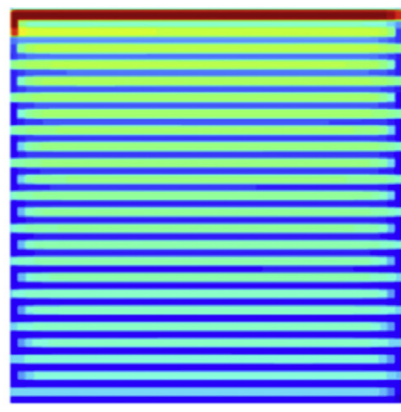

300 s

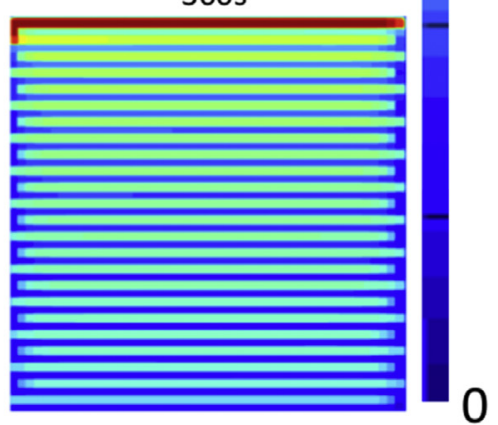

Fig. 8 - Spatial distribution of water content [pu] in the GDL of the cathode.

Figs. 6 and 7 show the current density of both states and the water content on each GDL. In Fig. 6 , it can be observed the transient curve on overall current density obtained using the model and the data captured experimentally. The simulation started with a water content fill of $25 \%$ in the cathode GDL and at $20 \%$ in the anode GDL.

The water evolution on each GDL during the simulation can be observed in Fig. 7. In this figure, it is shown how, on the cathode, water is mainly driven by the condensation and evaporation phenomena, but, on the anode, water content changes depending on the amount of water on the cathode and the overall current due to the electro-osmotic drag and the back diffusion.

As humidity is set constant, at saturation levels, on the anode channel there is continuous humidification, with non-constant condensation rate as a consequence of the humidity on the GDL (Eq. (5)). Despite anode gas kept at high humidification, the GDL water content is low, as a consequence of the electro-osmotic drag displacing water to the cathode where is removed in liquid form, when high current values occur, or in steam form when there is a low humidification state. 
$5 s$

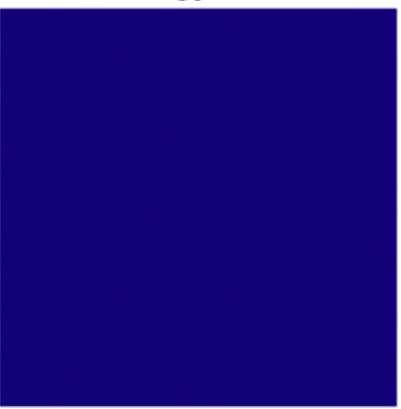

$10 s$

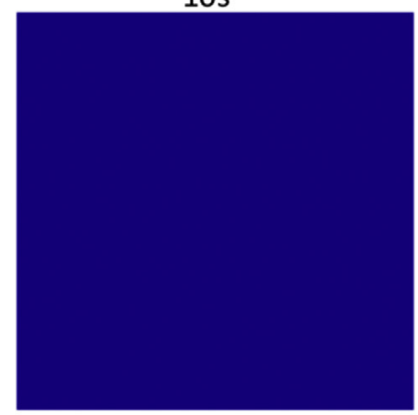

$15 s$

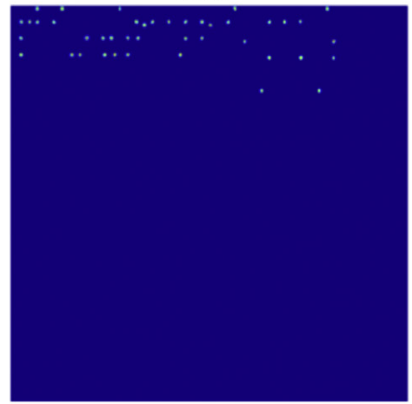

$25 \mathrm{~s}$

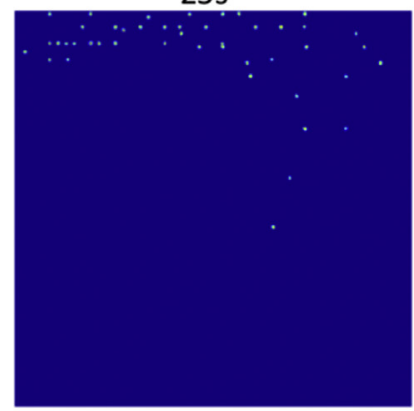

$40 s$

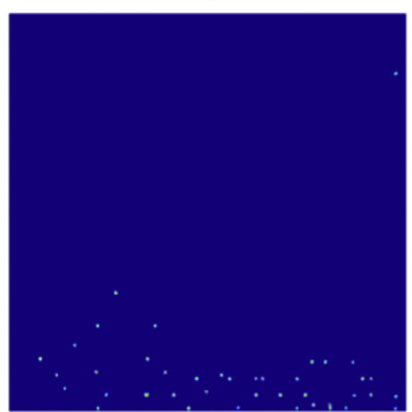

$80 \mathrm{~s}$

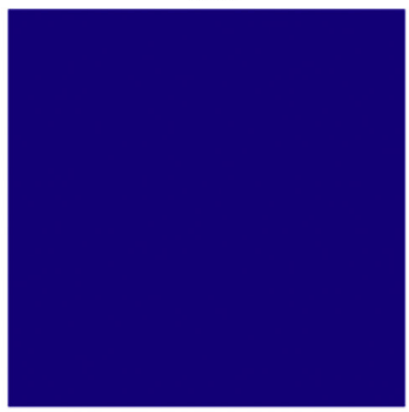

$140 s$

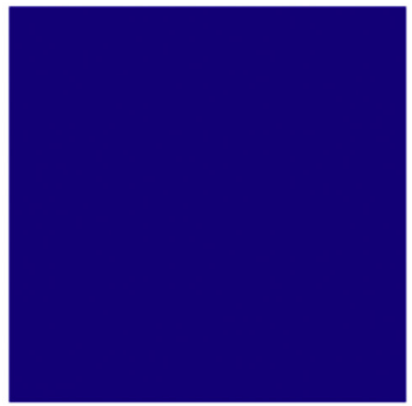

160 s

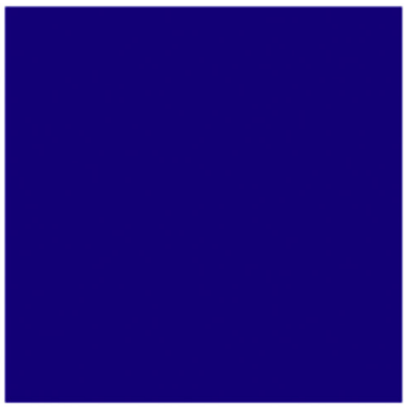

$225 s$

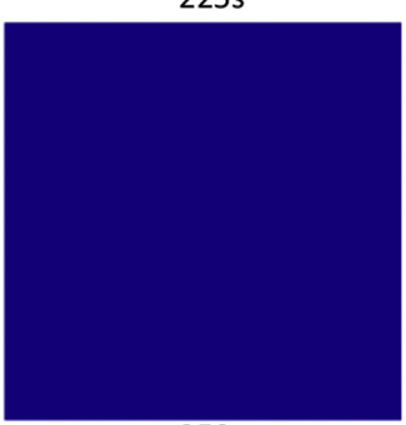

250s

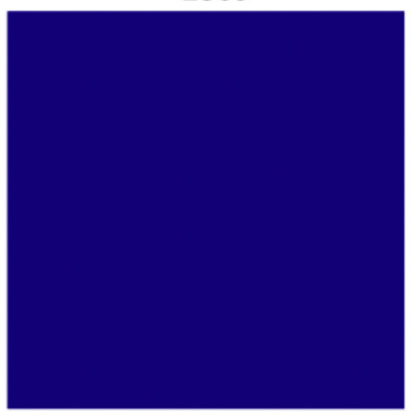

$275 s$

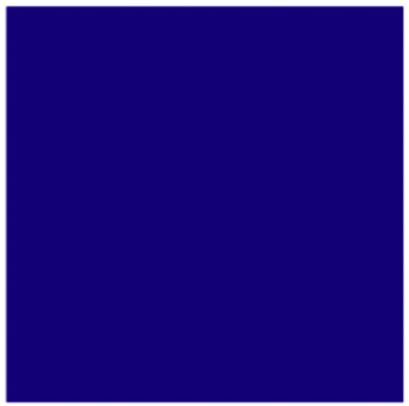

$300 \mathrm{~s}$

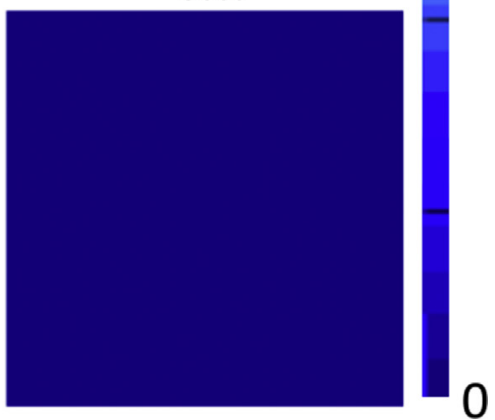

Fig. 9 - Water spatial distribution on the cathode GDL in different periods of time, from 0 to 1,1 being fully saturated of water and 0 no water.

In Fig. 6 are shown the experimental data extracted from $[8,35]$ experimentation and the simulated curve obtained using the model here presented. In Figs. 9 and 10, there can be observed the points marked on the [8] publication plus other intermediate results (time frames: 5, 10, 15, 25, 40, 80, 140, $160 \mathrm{~s}$ ).

In Figs. 9 and 10 it can be observed different frames of the transient simulation and the stages of water distribution on the cathode GDL, Fig. 9, and the current density of the cell, Fig. 10. These frames are taken during the first humidification and drying period of the simulation. It can be observed that, during the humidification, there is a spatial variation (bottom, high amounts of water, to top, low amounts of water) due to the distance to the cathode inlet.

The data is compared with the experimental data presented in [8]. It can be observed that the modeled behavior of the overall current density is similar to the obtained experimental data. The key parameters driving the dynamics between low and high states are a) the evaporation rates; b) the water uptake rate; and c) the current density of the cell. 
$5 s$

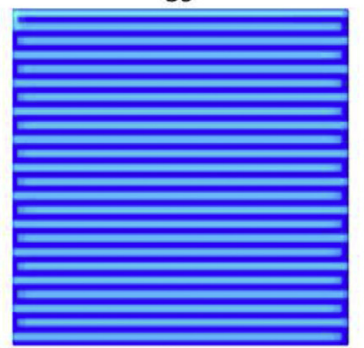

$10 \mathrm{~s}$

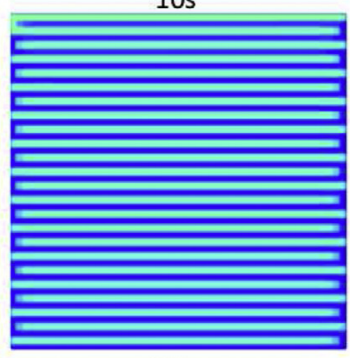

$15 \mathrm{~s}$

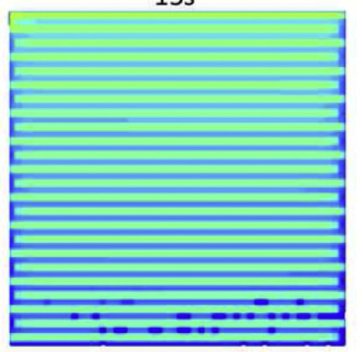

$25 \mathrm{~s}$

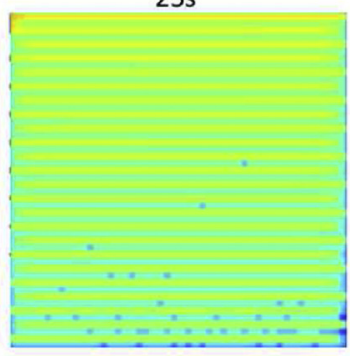

$40 s$

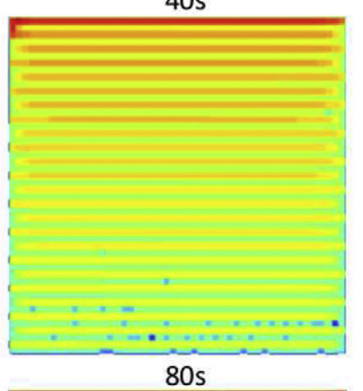

$80 \mathrm{~s}$

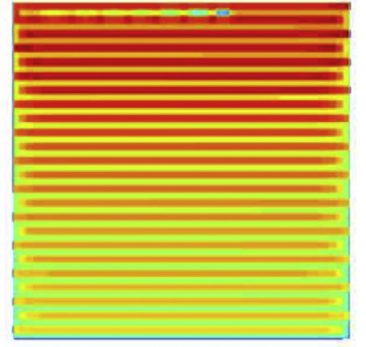

140 s

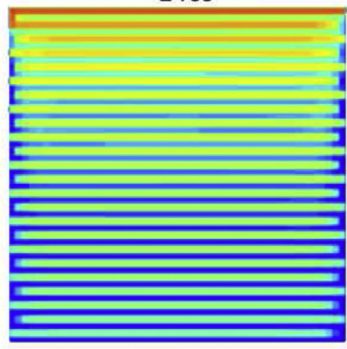

160 s

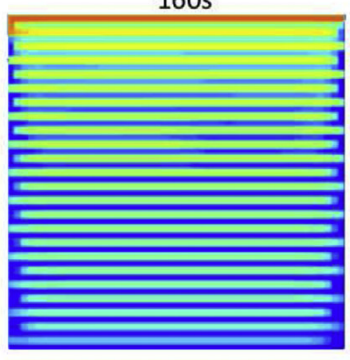

$225 s$

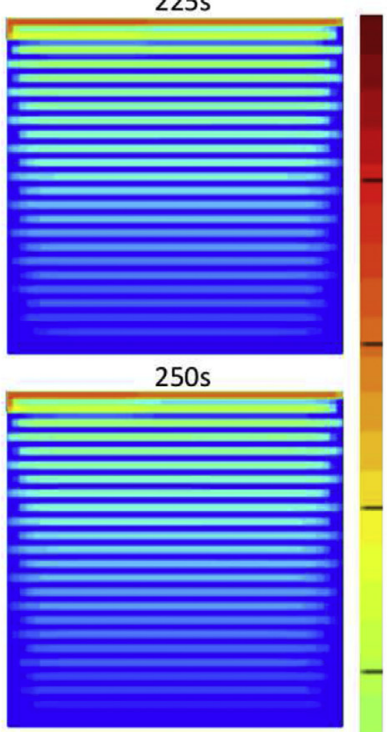

$275 s$

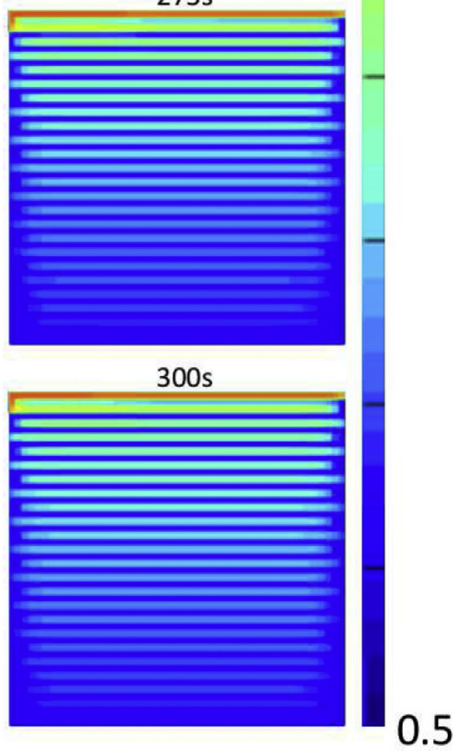

Fig. 10 - Current density spatial distribution $\left[\frac{\mathrm{A}}{\mathrm{cm}^{2}}\right]$ on the fuel cell in different periods of time.

Current density relates with generated water (Eq. (44)), which increases water content on the membrane, and the water content is only diminished by evaporation or water uptake. When setting the humidity too high, the capability of water to be removed as steam vanishes and water is only evacuated through capillarity, hence the amount of water in the GDL increases. The current density under the ribs, shown in Fig. 10, represents higher values compared with the values under the channels. These results agree with the experimental data obtained using differential segmented cells [36].

The capability of droplets simulation allows the evaluation of pressure drop fluctuations and the calculation of water evacuated through the channel in the form of liquid. As it is shown in Fig. 8, the amount of liquid water depends on the amount of humidity in the channel. At high fuel flows in the cathode channel, water droplets are removed fast from the channel. The fluctuations effect due to droplets may be significant when flows are lower, or channels are higher and wider.

\section{Conclusions}

A transient PEFC model coupling a channel model to simulate water droplets movement and pressure drop plus a GDL model capable of representing the gas and water diffusion has been developed and validated with experimental data provided by neutron imaging and segmented cell to evaluate the spatial distribution of liquid water and current density [8].

In this paper, a pseudo-3D channel and a 2D GDL coupled models are developed. The simulation procedure of the complete model is composed by a four-step solver; the channel solver calculates the pressure distribution in the channel, the 
movement, and cluttering of the water droplets; GDL solver calculates the gas and liquid water diffusion; the water link solver calculates the transport of water in the membrane between anode and cathode and the transport of water between the channel and the GDL; and the electrochemical solver calculates the electrochemical reactions of PEFC. The model and simulation procedure allows to obtain long-term dynamic simulations of liquid water droplets with low computational cost. The developed pseudo-3D transient PEFC model allows to simulate different operational setups (i.e. flows rates, relative humidity, and load profiles) in order to better understand the effects of water distribution in the cell. Moreover, in the model here presented the liquid water on the channel in the form of droplets is taken into account which is commonly neglected on other models [12-14,17] or taken into account with a high computational cost which require to high powerful computer clusters to solve them in a reasonable amount of time [37].

The serialized segmented model proposed enables the reduction the computational time to simulate the behavior of a complete fuel cell improving the modeling - results - tests and prototyping cycles, which allow faster development and learning processes.

This type of performance allows the simulation of different conditions in a short period of time before doing lab experiments.

The model developed in this paper is especially oriented to the study of the behavior of water in the fuel cell. New functionalities will be added to the model in the future.

\section{Acknowledgments}

This research was supported by the Ministerio de Economía y Competitividad of Spain, DPI2013-42941-R grant.

\section{Nomenclature}

\begin{tabular}{|c|c|}
\hline \multicolumn{2}{|c|}{ Greek } \\
\hline$\varepsilon$ & Porosity of the medium [unitless] \\
\hline$\gamma$ & Surface tension $[\mathrm{N} \cdot \mathrm{m}]$ \\
\hline$\kappa$ & Permeability $\left[\mathrm{m}^{2}\right]$ \\
\hline$\lambda_{m}$ & water content per sulfonic acid group [unitless] \\
\hline$\mu$ & Dynamic viscosity $[\mathrm{Pa} \cdot \mathrm{s}]$ \\
\hline$\rho$ & Density $\left[\mathrm{kg} \cdot \mathrm{m}^{-3}\right]$ \\
\hline$\rho$ & Density of the fluid $\left[\mathrm{kg} \cdot \mathrm{m}^{-3}\right]$ \\
\hline$\sigma_{m}$ & Membrane electric conductivity $\left[S \cdot \mathrm{m}^{-1}\right]$ \\
\hline$\tau$ & Porous medium tortuosity [unitless] \\
\hline$\theta$ & Contact angle [rad ] \\
\hline$\theta_{\mathrm{R}}$ & Droplet receding angle [rad] \\
\hline \multicolumn{2}{|c|}{ Roman } \\
\hline$a_{k}$ & Water activity [unitless] \\
\hline$b_{1}$ & Membrane electric conductivity parameter 0.00326 \\
\hline$b_{2}$ & Membrane electric conductivity parameter 0.005139 \\
\hline$b_{3}$ & Membrane electric conductivity parameter 1268 \\
\hline$c_{d}$ & Droplet chord lentgh $[\mathrm{m}]$ \\
\hline$c_{t}$ & $\begin{array}{l}\text { Compressibility of the fluid plus the compressibility } \\
\text { of the GDL [unitless] }\end{array}$ \\
\hline
\end{tabular}

adh

bd

cath
Gas diffusion layer coverage by water [unitless] Diameter $[m]$ Binary diffusion component between $i$ and $j$ components $\left[\mathrm{m}^{2} \cdot \mathrm{s}^{-1}\right]$ Closed cell potential [V]

Reversible Gibbs potential [V]

Roughness of the surface where the fluid is flowing [mm]

Faraday constant $96485\left[\mathrm{~A} \cdot \mathrm{s} \cdot \mathrm{mol}^{-1}\right]$

Force $[N]$

Darcy friction coefficient [unitless]

Gibbs free energy [J]

Channel height $[\mathrm{m}]$

Droplet height $[\mathrm{m}]$

Leverett's function value [unitless]

Current density $\left[\mathrm{A} \cdot \mathrm{cm}^{-2}\right]$

Activation current density $\left[A \cdot \mathrm{cm}^{-2}\right]$

Evaporation/condensation constant $\left[\mathrm{Pa}^{-1} \cdot \mathrm{s}^{-1}\right]$ and $\left[\mathrm{s}^{-1}\right]$

\section{Length $[m]$}

Molar weight $\left[\mathrm{g} \cdot \mathrm{mol}^{-1}\right]$

Number of moles exchanged [unitless]

Number of moles exchanged [unitless]

Electro-osmotic drag coefficient [unitless]

Pressure $[\mathrm{Pa}]$

Absorption liquid flow $\left[\mathrm{m}^{3} \cdot \mathrm{s}^{-1}\right]$

Gas constant $\left.8.31 \mathrm{~J} \cdot \mathrm{mol}^{-1} \cdot \mathrm{K}^{-1}\right]$

Radius [m]

Droplet radius $[\mathrm{m}]$

Reynolds number [unitless]

Liquid water fraction inside the GDL [unitless]

Temperature $[\mathrm{K}]$

Time [s]

Thickness $[\mathrm{m}]$

Speed of the fluid $\left[\mathrm{m} \cdot \mathrm{s}^{-2}\right]$

Volume $\left[\mathrm{m}^{3}\right]$

Over potential voltage [V]

Droplet width [m]

Molar fraction [unitless]

Position of the droplet center of masses $[\mathrm{m}]$

Advancing

Anode

Activation

Adhesion

Back diffusion

Cathode

\section{Capillar}

Concentration

Condensation constant

Adhesion

Electrosmotic

Evaporation constant

Fuel cell

Gas

Hydraulic, diameter

Liquid

Membrane

Ohmic

Receding

Static 
sat wmin

\section{R E F E R E N C E S}

[1] Schillberg CH, Kandlikar SG. A review of models for water droplet detachment from the gas diffusion layer-gas flow channel interface in PEMFCs. In: ASME 5th int. conf. nanochannels, microchannels, and minichannels, vol. 4272X; 2007. p. 1-12.

[2] Kätzel J, Markötter H, Arlt T, Klages M, Haußmann J, Messerschmidt M, Kardjilov N, Scholta J, Banhart J, Manke I. Effect of ageing of gas diffusion layers on the water distribution in flow field channels of polymer electrolyte membrane fuel cells. J Power Sources 2016;301:386-91.

[3] Siefert NS, Litster S. Voltage loss and fluctuation in proton exchange membrane fuel cells: the role of cathode channel plurality and air stoichiometric ratio. J Power Sources 2011;196(4):1948-54.

[4] Liu X, Guo H, Ye F, Ma CF. Water flooding and pressure drop characteristics in flow channels of proton exchange membrane fuel cells. Electrochim Acta 2007;52(11):3607-14.

[5] Randrianarizafy B, Schott P, Chandesris M, Gerard M, Bultel Y. Design optimization of rib/channel patterns in a PEMFC through performance heterogeneities modelling. Int J Hydrogen Energy 2018;43:8907-26.

[6] Barati S, Khoshandam B, Mehdipour Ghazi M. An investigation of channel blockage effects on hydrogen mass transfer in a proton exchange membrane fuel cell with various geometries and optimization by response surface methodology. Int J Hydrogen Energy 2018;43:21928-39.

[7] Bao Z, Niu Z, Jiao K. Numerical simulation for metal foam two-phase flow field of proton exchange membrane fuel cell. Int J Hydrogen Energy 2019;44:6229-44.

[8] García-Salaberri P, Sánchez D, Boillat P, Vera M, Friedrich K. Hydration and dehydration cycles in polymer electrolyte fuel cells operated with wet anode and dry cathode feed: a neutron imaging and modeling study. J Power Sources 2017;359:634-55.

[9] Chen Y-S, Peng H. A segmented model for studying water transport in a PEMFC. J Power Sources 2008;185(2):1179-92.

[10] Celep GK, Dincer K. An overview of the gas diffusion layer in proton exchange membrane fuel cells: how its nanostructural characteristics affect performance. In: 4th int. symp. innovative tech. eng. sci.; 2016.

[11] Gallo Stampino P, Molina D, Omati L, Turri S, Levi M, Cristiani C, Dotelli G. Surface treatments with perfluoropolyether derivatives for the hydrophobization of gas diffusion layers for PEM fuel cells. J Power Sources 2011;196:7645-8.

[12] Schumacher JO, Eller J, Sartoris G, Colinart T, Seyfang B. $2+1 \mathrm{D}$ modelling of a polymer electrolyte fuel cell with glassycarbon microstructures. Math Comput Model Dyn Syst 2012;18:355-77.

[13] Macedo-Valencia J, Sierra J, Figueroa-Ramírez S, Díaz Méndez S, Meza M. 3D CFD modeling of a PEM fuel cell stack. Int J Hydrogen Energy 2016;41.

[14] Lee PH, Hwang SS. Performance characteristics of a PEM fuel cell with parallel flow channels at different cathode relative humidity levels. Sensors 2009;9(11):9104-21.

[15] Jarauta A, Secanell M, Pons-Prats J, Ryzhakov P, Idelsohn SR, Oñate E. A semi-analytical model for droplet dynamics on the GDL surface of a PEFC electrode. Int J Hydrogen Energy 2015;40(15):5375-83.

[16] Esposito A, Pianese C, Guezennec YG. Coupled modeling of water transport and air-droplet interaction in the electrode of a proton exchange membrane fuel cell. J Power Sources 2010;195(13):4149-59.

[17] Ghorbani B, Vijayaraghavan K. 3D and simplified pseudo-2D modeling of single cell of a high temperature solid oxide fuel cell to be used for online control strategies. Int J Hydrogen Energy 2018;43:9733-48.

[18] Pasaogullari U, Wang C. Liquid water transport in gas diffusion layer of polymer electrolyte fuel cells. J Electrochem Soc 2004;151:23425-33.

[19] Raman K, Mondal B, Li X. Water droplet transport in single gas flow channel of PEM fuel cell. Int J Adv Ther Sci Eng 2011;2:27-33.

[20] Benziger J, Nehlsen J, Blackwell D, Brennan T, Itescu J. Water flow in the gas diffusion layer of pem fuel cells. J Membr Sci 2005;261:98-106.

[21] Tamayol A, Bahrami M. Water permeation through gas diffusion layers of proton exchange membrane fuel cells. J Power Sources 2011;196(15):6356-61.

[22] Shimpalee S, Zee JV. Numerical studies on rib and channel dimension of flow-field on PEMFC performance. Int $\mathrm{J}$ Hydrogen Energy 2007;32(7):842-56.

[23] Santamaria A, Das P, MacDonald JC, Weber A. Liquid-water interactions with gas-diffusion-layer surfaces. J Electrochem Soc 2014;161:F1184-93.

[24] Das PK, Santamaria AD, Weber AZ. Interactions between liquid-water and gas-diffusion layers in polymer-electrolyte fuel cells. In: The 6th BSME int. conf. thermal engeering, vol. 105; 2015. p. 751-6.

[25] Chaudhary S, Sachan VK, Bhattacharya PK. Two dimensional modelling of water uptake in proton exchange membrane fuel cell. Int J Hydrogen Energy 2014;39(31):17802-18.

[26] Whitaker S. Flow in porous media i: a theoretical derivation of Darcy's law. Transp Porous Media 1986;1:3-25.

[27] Lindstrom M, Wetton B. A comparison of fick and maxwellstefan diffusion formulations in PEMFC cathode gas diffusion layers. Heat Mass Transf 2013;53.

[28] Cheema T, Kim GM, Young Lee C, Kwak M, Bum Kim H, Woo Park C. Effects of composite porous gas-diffusion layers on performance of proton exchange membrane fuel cell. Int $\mathrm{J}$ Precis Eng Man-Gt 2014;1:305-12.

[29] Hussaini I, Wang C. Measurement of relative permeability of fuel cell diffusion media. J Power Sources 2010;195(12):3830-40.

[30] Mondal B, Jiao K, Li X. Three-dimensional simulation of water droplet movement in PEM fuel cell flow channels with hydrophilic surfaces. Int J Energy Res 2010;35(13):1200-12.

[31] Arabí ÀJ. Analysis of droplet dynamics on the GDL surface of a PEM fuel cell cathode. Master's thesis, UPC. 2013.

[32] Kunusch C, Puleston PF, Mayosky MA, Moré JJ. Characterization and experimental results in PEM fuel cell electrical behaviour. Int J Hydrogen Energy 2010;35(11):5876-81.

[33] Springer T, Zawodzinski TA, Gottesfeld S. Polymer electrolyte fuel cell model. J Electrochem Soc 1991;138:2334-42.

[34] Thanh Nguyen P, Berning T, Bang M, Djilali N. A threedimensional model of pem fuel cells with serpentine flow channels. INIS 2003;35.

[35] Sanchez DG, Diaz DG, Hiesgen R, Wehl I, Friedrich KA. Oscillations of PEM fuel cells at low cathode humidification. J Electroanal Chem 2010;649(1):219-31.

[36] Shrivastava U, Tajiri K. Sources of current density distribution in the land-channel direction of a PEMFC. J Elecrochem Soc 2016;163:F1072-83.

[37] Ferreira RB, Falcão D, Oliveira V, Pinto A. 1D+3D two-phase flow numerical model of a proton exchange membrane fuel cell. Appl Energy 2017;203:474-95. 